\title{
An Empirical Study on the Effectiveness of the Lexical Approach to Improving Writing in SLA
}

\author{
Jingwei Tang \\ Department of Foreign Languages, Shandong Jiaotong University, Jinan, China \\ Email: jingweitang@126.com
}

\begin{abstract}
The study tries to explore the effectiveness of the lexical approach to improving writing in SLA. In order to find out what effects the lexical approach can have on the writing in SLA, the author conducts a teaching experiment with an experimental class and a control class. A pre-test and a post-test are used as the tools to collect the data. SPSS is used to analyze the data in the experiment. Results of the experiments show that a lexical approach to SLA teaching can enhance students' awareness of lexical chunks, significantly improve their frequency of using lexical chunks, and conduce to raise their level of English writing.
\end{abstract}

Index Terms - the lexical approach, SLA, writing competency, lexical chunks

\section{INTRODUCTION}

Writing is one of the four basic language skills, which occupies an extremely important position in second language teaching. It also plays essential roles in cultivating students' comprehensive language competence and increasing students' overall cultural awareness. However, writing ability is rather difficult to be developed; although teachers and students have invested a lot of time and energy, the result is not always satisfactory. In the daily teaching, it's not unusual for the teachers to find that despite having mastered a large quantity of grammar rules and vocabulary, many students still use some very simple words, phrases and sentences, or translate word for word to express themselves. The reason may be that there is much disconnection between language input and output in the process of SLA, thus how to help students to output language effectively, and transform the language knowledge into language skills becomes an urgent and essential task.

Many researchers (Lay, 1982; Uzawa \&Cumming, 1989) have found that in second language writing low proficiency students are often dependent on their mother tongue thinking, and they use native language to organize ideas, and then literally translate them into the target languages. This means that in the writing in SLA the mother tongue thinking and second language thinking are mixed and interacted consistently, which tends to result in misnomer, sentence errors, bad coherence, and vague expression. Some language researchers (Nattinger \&De Carrico, 1992; Lewis, 1993) find there are a large number of word clusters with a high ratio of reproduction in language. After collecting, analyzing and deconstructing these phrases from language materials and language communication, language learners get access to some language units and rules which can be reused in actual communication. Based on this, some new sentences can be produced, leading to more abundant communicative forms and more influent communicative process. These fixed and semi-fixed phrases are called lexical chunks. By analyzing and summarizing research in this area, researchers understand the roles and significance of lexical chunks in language learning in more depth and more thoroughly and a lexical approach is thus put forward.

\section{BACKGROUND}

\section{A. The Lexical Approach}

Michael Lewis (1993), who puts forward the lexical approach, suggests that lexis is the basis of language instead of grammar-lexis is misunderstood in language teaching when grammar is traditionally assumed as the basis of language and that mastery of the grammatical system is a prerequisite for effective communication. According to Lewis (1993), the key principle of a lexical approach is that "language consists of grammaticalized lexis, not lexicalized grammar."(p.36). One of the central organizing principles of any meaning-centered syllabus should be lexis. In Lewis' theory of lexis, lexical chunks are paradigm grammar and the acquisition of language knowledge and improvement of communicative abilities depend on the expansion of vocabulary, the abilities of collocation, and the mastery of basic vocabulary and language structures. Lexical chunks are the smallest unit in verbal communication as well as a perfect unit of language learning.

In the lexical approach, lexical chunks in its various types are thought to play an essential role in native and second language teaching and learning. Nattinger (1980) suggests that teaching should be based on the idea that language production is the piecing together of ready-made units appropriate for a particular situation.

Lewis (1997) suggests the following taxonomy of lexical items:

- polywords (e.g., a couple of; at times; in turn) 
- collocations, or word partnerships (e.g., strongly recommended; meet the minimum standards)

- institutionalized utterances (e.g., I'll get it; We'll see; That'll do; If I were you....; Would you like a cup of coffee?)

- sentence frames and heads (e.g., It is not as... as you think; It's said/ reported/ suggested that...) and even text frames (e.g., The aim of the thesis is to explore...; On one hand ..., on the other...)

\section{B. Language Information Theory}

Language information processing theory holds that language learning is a non-automated information processing process of cognitive activity. The process is divided into five stages: input, attention, analysis, memorization and output. Cognitive psychologists believe that the brain's methods of processing input information are bottom-up and top-down mode. Bottom-up mode features attention to details, which is a series of process from the lower to the higher, from decoding the words to accessing the final information; top-down mode highlights the recognition of the overall structure, emphasizing the roles of accumulated background knowledge in understanding the language information. These two methods are interrelated, and interacted in helping to comprehend the language information with the layers ranging from morphology and syntax to discourse. The top-down mode of learning lexical chunks accelerates the application of chunks from the lexical and syntactic level to the discourse level, resulting in improving the learners' writing competency (Yu Xiulian, 2008).

\section{Methodology}

\section{A. Purpose of the Study}

The study tries to explore how to apply the lexical approach to college English writing and then examine the effects that lexical chunks have on improving college students' writing competency.

\section{B. Participants}

Participants in this experiment are sophomore non-English majors in two parallel classes: Class A (42) and Class B (43) with a total of 85 students. Class A is the experimental class and Class B is the control class and both of two classes are taught by the author.

\section{Method}

For the experimental class, the author chooses New Horizon College English as the text book, adopts the lexical method to teaching and consciously cultivates students' abilities of identifying and applying lexical chunks to help them to develop their writing abilities through a series of teaching and learning activities, while for the control class, the conventional method of teaching is implemented with the same text books. Results of the study are primarily reflected through students' writing performance in a pre-test and a post-test, and SPSS11.5 is used for statistics and analysis. After the experiment, writing performance of the two classes will be compared and contrasted through quantitative analysis. The experiment lasts 16 weeks.

\section{Procedure}

\section{Pre-test}

At the beginning of the academic term, students in the two classes were asked to write a composition of no less than 120 words with the title Part-time Jobs for College Students within 30 minutes. Full mark of the writing is 15 . Students were advised to undertake the task seriously and carefully, as scores of their writings would be included in the final assessment on their daily performance. Writings of the students are scored by two experienced teachers and an average score of each composition is adopted.

2. Teaching design and teaching activities (based on the lexical approach) in the experimental class

According to the lexical approach, language class activities are divided into three phases: Observation - Hypothesis - Experiment. Lewis (1997) states that focus of the language teaching should shift from grammar to vocabulary, and teachers should encourage students to master a large number of necessary vocabularies according to their needs while providing students with meaningful and comprehensible input materials so that students can master vocabulary in the contexts. For teachers, to increase students' sensitivity of vocabulary intentionally and teach students to identify lexical chunks are encouraged. In the first three weeks, the author introduced the knowledge about lexical chunks to students, including the definition, categories and functions of chunks, and ways to collect chunks. By adopting the lexical approach, teaching activities are designed as follows (take the text Cultural Difference in Western and Japanese Decision-making as an example).

a. Pre-reading activities

Before reading the passage, students are asked to discuss and answer the following questions:

- Have you ever heard of premarital agreements? What do you think they are for?

- Do you think premarital agreement will take the romance out of marriage for the man as well as the woman?

- Would you ask for a premarital agreement before your marriage? Why or why not?

b. While-reading activities 
In this stage, it's better for the teachers to ask students to have a global reading first so that students can have an overall understanding of the main idea and know about the whole structure of the passage, which is beneficial to students' writing. Then a detailed reading activity is followed.

In this part, teaching activities takes the lexical chunks as the index with the sequence of observation, hypothesis and experiment. Through the recognition, learning and application of lexical chunks, students are expected to master and apply them efficiently, so that their language competency can be improved.

\section{Recognizing the lexical chunks}

At the beginning of the study, some knowledge about chunks has been taught to the students. While reading a passage, a student is firstly asked to identify and find out the chunks in it with the purpose of shifting his focus from grammar and independent words to chunks. Focusing more attention on lexical chunks rather than on the language rules in SLA to draw the rules of utilizing language is rather similar to the way of mother tongue acquisition.

- polywords: in contrast to; on some way; owing to; in a pinch

- collocations: come to grips with; work for; be related to; distinguish from; set up; fall through; press for; wonder at; lag behind; exert oneself; at the least; be superior/ inferior to; develop from; from one's point of view; set up; deal with; be based on; be true of; achieve harmony; in a different perspective, be secondary to; press for; be frustrated by; take great pride in; convert to; be feasible to

- sentence frames and heads: This is of extreme importance when doing something; First...Second...; The difference is that...; It is ...who...; By that I mean...

This part belongs to the observation stage and aims to guide students to feel the characteristics of the English language and pave the way for utilizing lexical chunks.

\section{Practicing and utilizing the lexical chunks}

This part belongs to the hypothesis and experiment stage and aims at training students to perceive and internalize the usage of lexical chunks in various ways. In this stage, the teacher should devise various ways to guide students to practice, utilize and master the lexical chunks. The following ways are advised.

- Sentence completion: From my point of view, the "you to you" approach is superior to the "I to you" approach.

- Sentence making: This is of extreme importance when trying to achieve harmony in a company.

- Sentence translation: Use "come to grips with" to make a sentence.

- Text retelling or abbreviating: Use the lexical chunks in the passage to retell or abbreviate the text.

- Text reciting: Students are expected to recite the parts which contain many of the chunks in the text.

With the recognition and utilization of chunks, students are expected to master the lexical chunks in practice, which contributes to the fluency of language output.

c. Post-reading activities

In the post-reading activities, students are expected to consolidate the chunks learned previously and then make an extensive reading to collect and master more chunks further. Language learning is a process of accumulation of language knowledge. With more chunks stored in the brain, it's more likely for the students to output language in faster steps and the more accuracy and fluency of the writing can be realized. In order to encourage students to collect chunks more willingly and actively, they are asked to exchange each others' chunks found in their extensive reading after class. Students are also encouraged to make class reports orally and literally in class with the chunks they have obtained in the extensive reading as the consolidating way.

3. Post-test

In order to determine the effect of the lexical approach to writing in SLA, a post-test is taken by students in the two classes. All are asked to write a composition of no less than 120 words with the title Psychological Problems among College Students within 30 minutes. Writings of the students are scored by two experienced teachers and an average score of each composition is adopted.

\section{DataAnalysis AND Results}

In order to investigate the effect of the study, a number of descriptive and inferential statistical procedures are initiated. The results obtained through such analysis will be explained and depicted in the following section. A premise of the study is that the experimental group and the control group are comparable and the difference between the two classes is not significant before the experiment. In other words, the two groups of students are expected to indicate no significant differences concerning the levels of writing and they should be of homogeneity concerning the writing competency before the study. In order to check the homogeneity, a pre-test is given to the two classes to judge and evaluate their levels of writing.

TABLE 1

DESCRIPTIVE STATISTICS ON PERFROMANCE ON PRE-TEST

\begin{tabular}{|l|l|l|l|}
\hline & $\mathrm{N}$ & Mean & Std. Deviation \\
\hline Class A & 42 & 8.67 & 1.57 \\
Class B & 43 & 8.78 & 1.76 \\
\hline
\end{tabular}


TABLE 2

INDEPENDENT SAMPLES TEST OF RESULTS OF PRE-TEST

\begin{tabular}{|l|l|l|l|l|l|}
\hline & Group & N & t & Sig. (2-tailed) & Mean Difference \\
\hline \multirow{2}{*}{ Pre-test } & Class A & 42 & -0.021 & \multirow{2}{*}{0.192} & -0.11 \\
\cline { 2 - 7 } & Class B & 43 & & -1 \\
\hline
\end{tabular}

Table 1 indicates that the means are statistically very close to each other on the pre-test (8.67 and 8.78). Hence, it can be inferred that the students in the two classes don't differ greatly from one another in terms of their writing performance. In the dependent samples test of results on the pre-test $t$-value is -0.021 and $p$ is 0.192 . Table 2 reveals that the value of $t$ is not significant at the level of $p(>0.05)$, which means the participants' almost equal writing competency statistically.

TABLE 3

DESCRIPTIVE STATISTICS ON PERFROMANCE ON POST-TEST

\begin{tabular}{|l|l|l|l|}
\hline & $\mathrm{N}$ & Mean & Std. Deviation \\
\hline Class A & 42 & 10.29 & 2.016 \\
Class B & 43 & 9.36 & 1.922 \\
\hline
\end{tabular}

TABLE 4

INDEPENDENT SAMPLES TEST OF RESULTS OF POST-TEST

\begin{tabular}{|l|l|l|l|l|l|}
\hline & Group & N & t & Sig. (2-tailed) & Mean Difference \\
\hline \multirow{2}{*}{ Post-test } & Class A & 42 & 2.32 & \multirow{2}{*}{0.001} & 0.93 \\
\cline { 2 - 3 } & Class B & 43 & & \multirow{2}{*}{} \\
\hline
\end{tabular}

From Table $3 \& 4$, we can find that the average score of experimental class is 10.29 , which is 0.93 more than the average score of the control class (9.36). The independent samples test of the results on the post-test shows that the two groups are significantly different at the level of $0.001(<0.05)$, from which we can deduce that after the lexical approach is adopted in SLA, students' writing performance is greatly improved in the experimental class, while the traditional approach attributes no significant progress to improving students' writing competency in the control class.

TABLE 5

PAIRED SAMPLES TEST OF THE RESULTS OF PRE-TEST AND POST-TEST

\begin{tabular}{|l|l|l|l|l|l|}
\hline Group & Mean Difference & Std. Deviation & t & df & Sig. (2-tailed) \\
\hline Class A & -1.62 & 2.711 & -5.014 & 41 & 0.000 \\
\hline Class B & -0.58 & 2.426 & -1.882 & 42 & 0.065 \\
\hline
\end{tabular}

Table 5 shows that the average score of experimental class on the post-test is 1.62 more than that on the pre-test while the average score of the control class on the post-test is only 0.58 more than that on the pre-test. For the experimental class, $t$ is significant at the level of $p=0.000$, while for the control class $t$ is not significant at the level of $\mathrm{p}=0.065$. It can be inferred from Table 5 that although the two classes' writing performance is improved after a term's learning, only the writing abilities of the experimental class are significantly improved.

\section{DiSCUSSION AND CONCLUSION}

From the analysis above, we can come to find that the lexical approach to improving students' writing abilities is rather effective. The reason may lie as follows. First of all, the lexical approach focus on the awareness of using lexical chunks, which can bring benefits to the internalization of language input and the language acquisition. Only when the learners themselves are aware of the gap between them and the native speakers of English, can it be possible for them to work harder to reduce that gap. Secondly, the lexical approach emphasizes learning words by heart by regarding them as a whole unit stored in memory. Learners can pick them up as a whole if needed rather than fix them up temperately according to grammatical rules, which can reduce the pressure of coding language, save the brain a lot of time and effort to process information, thereby enhance the fluency of expression. Lewis (1997) says, "Fluency is based on the acquisition of a large number of fixed or semi-fixed prefabricated blocks, which is the basis for language innovation." (p.120). Also, as a combination of grammar, semantics and context, lexical chunks picked up as a whole can significantly reduce the number of wrong semantic collocation, and improve the accuracy and authentic nature of language.

The experiment shows that a lexical approach to SLA teaching can enhance students' awareness of lexical chunks, significantly improve their frequency of using lexical chunks, and conduce to raise the level of English writing. The result of the study gives clues to college English class teaching, especially to teaching writing. First, it shows the lexical approach is practical and effective; Secondly, to follow the approach to teaching, teachers guided by the lexical chunk theory should first change their teaching concepts, guide students to establish a sense of lexical chunks, and make the opportunities to help students to use lexical chunks creatively in the communication with a variety of teaching methods to improve students' pragmatic and communicative competency. Thirdly, due to the large number of lexical chunks, it is not enough to collect, practice and master lexical chunks in class. At the same time, students are expected to learn to use dictionaries, corpus and net resources to master lexical chunks after class. Of course, it still remains to be further 
studied how to apply the lexical approach to every aspect of language teaching better to improve students' comprehensive competency.

\section{APPENDIX A PRE-TEST WRITING}

Directions: for this part, you are allowed thirty minutes to write a composition on the topic Part-time Jobs for College Students. You should write at least 120 words, and base your composition on the outline given below:

1. Currently, many students take part-time jobs in their spare time in the college campus.

2. Peoples' ideas are divided as whether they should take the part-time jobs.

3. In my opinion ...

\section{APPENDIX B POST-TEST WRITING}

Directions: for this part, you are allowed thirty minutes to write a composition on the topic Psychological Problems among College Students. You should write at least 120 words, and base your composition on the outline given below:

1. At present, many students are suffering from serious psychological problems.

2. Causes for these psychological problems are ...

3. What measures should be taken to address these issues.

\section{REFERENCES}

[1] Altenberg, B. \&Granger, S. (2001). The Grammatical and Lexical Patterning of "make" in Native and Non-native Student Writing. Applied Linguistics 22,173- 194.

[2] Cowie, A. P. (1998). Phraseology: Theory, Analysis, and Applications. Oxford: Oxford University Press.

[3] Ellis R. (1999). The Study of Second Language Acquisition. Shanghai: Shanghai Foreign Languages Education Press.

[4] Girard, M. \& Sionis, C. (2004). The Functions of Formulaic Speech in the L2 Class. Pragmatics 14/2, $31-53$.

[5] Howarth, P. (1998). Phraseology and Second Language Proficiency. Applied Linguistics 19/ 1, $24-44$.

[6] Krashen S D. \& R Scarcella. (1978). On Routines and Patterns in Language Acquisition and Performance. Language Learning, 12/2, 283-300.

[7] Lay, N. (1982). Composing Processes of Adult ESL Learners: A Case Study. TESOL Quarterly, 16, 406 407.

[8] Lewis, M. (1997). Implementing the Lexical Approach: Putting Theory into Practice. England: Language Teaching Publications.

[9] Lewis, M. (1993). The Lexical Approach. England: Language Teaching Production.

[10] Lewis, M. (2000). Language in the Lexical Approach. In M. Lewis, Teaching Collocation: Further Developments in the Lexical Approach. Hove: Language Teaching Publications. 126-54.

[11] Liao, Yan \& Y. Fukuya. (2004). Avoidance of Phrasal Verbs: The Case of Chinese Learners of English. Language L earning, 54, 193-226.

[12] Liontas, J. I. (2002). Exploring Second Language Learners’ Notions of Idomaticity. System, 30, $289-313$.

[13] Nattinge, J. R. \& DeCarrico, J. S. (1992) Lexical Phrases and Language Teaching. London: Oxford University Press.

[14] Nesselhaluf, N. (2003). The Use of Collocations by Advanced Learners of English and Some Implications for Teaching. Applied Linguistics, 24/2, 223- 242.

[15] Pawley, A. \& F. H. Syder (1983). Two Puzzles for Linguistic Theory: Nativelike Selection and Nativelike Fluency. In J. C. Richards \& R. W. Schmidt, Language and communication. London: Longman. 191-225.

[16] Peters, A. (1983). The Units of Language Acquisition. Cambridge: Cambridge University Press.

[17] Powell, M. (1996). Business Matters: The Business Course with a Lexical Approach. Hove: Language Teaching Publications.

[18] Schegloff, E. A., I. Koshik, S. Jacoby \& D. Olsher (2002). Conversation Analysis and Applied Linguistics. Annual Review of Applied Linguistics 22, 3-31.

[19] Sinclair, J. (1991). Corpus, Concordance, Collocation. Oxford: Oxford University Press.

[20] Sinclair, J. \& A. Renouf (1988). A Lexical Syllabus for Language Learning. In R. Carter \& M. McCarthy, Vocabulary and Language Teaching. London: Longman. 140-58.

[21] Skehan, P. (1998). A Cognitive Approach to Language Learning. Shanghai: Shanghai Foreign Language Educational Press.

[22] Swales, J. M. (1990). Genre Analysis: English in Academic and Research Settings. London: Cambridge University Press.

[23] Thomas, J. (1983). Cross-cultural Pragmatic Failure. Applied Linguistics, 4/2, 91-112.

[24] Uzawa, K. \&A. Cumming. (1989). Writing Strategies in Japanese as a Foreign Language: Lowering or Keeping up the Standards. The Canadian Modern Language Review, 46(1), 178 194.

[25] Widdowson, H. (2000). On the Limitations of Linguistics Applied. Applied Linguistics, 21.1, 3-25.

[26] Wildner-Bassett, M. E. (1984). Improving Pragmatic Aspects of Learners' Interlanguage: A Comparison of Methodological Approaches for Teaching Gambits to Advanced Adult Learners of English in Industry. Tübingen: Narr Press.

[27] Williams, M. (1988). Language Taught for Meetings and Language Used in Meetings: Is There Anything in Common? Applied Linguistics, 9.1, 45-58.

[28] Willis, D. (1990). The Lexical Syllabus: A New Approach to Language Learning. London: Collins ELT.

[29] Willis, J. (1998). Concordances in the Classroom without a Computer: Assembling and Exploiting Concordances of Common Words. In B. Tomlinson, Materials Development in Language Teaching. London: Cambridge University Press.

[30] Wray, A. (1999). Formulaic Language in Learners and Native Speakers. Language Teaching, 32.4, $213-31$.

[31] Wray, A. (2000) Formulaic sequences in second language teaching: principle and practice. Applied Linguistics, 21.4, 463-89. 
[32] Wray, A. \& Perkins M.R. (2000). The Functions of Formulaic Language: An Integrated Model. Language and Communication, $20.1,1-28$

[33] Yorio, C.A. (1980) Conventionalized language forms and the development of communicative competence. TESOL Quarterly 14.4: 433-42.

[34] Yu Xiulian. (2008). An Experimental Study on the Lexical Approach to Improving English Language Competency. World of Foreign Languages, 3, 54-61.

Jingwei Tang was born in Linyi, China in 1977. He is a second year M.A candidate of Linguistics in Shandong University. $\mathrm{He}$ is currently a Lecturer in the Department of Foreign Languages, Shandong Jiaotong University, Jinan, China. His research interests include second language acquisition and pragmatics. 